\title{
ALLELOPATHIC RELATIONS OF SELECTED CEREAL AND VEGETABLE SPECIES DURING SEED GERMINATION AND SEEDLING GROWTH
}

\author{
Biljana M. Bojović and Dragana Z. Jakovljević \\ Department of Biology and Ecology, Faculty of Science, University of Kragujevac, \\ Radoja Domanovića 12, 34000 Kragujevac, Republic of Serbia \\ E-mail: draganajakovljevic@ymail.com
}

(Received April 2, 2015)

\begin{abstract}
Allelopathy is the direct or indirect harmful effect which one plant produces on another through the production of chemical compounds that escape into the environment. In the presence paper allelopathic relationships were determined in three cereals - wheat (Triticum aestivum L.), barley (Hordeum vulgare L.), oat (Avena sativa L.) and vegetable crops - spinach (Spinacia oleracea L.), radish (Raphanus sativus L.), pepper (Capsicum annum L.). In addition to the percentage of germination, allelopathic potential was tested measuring root and stem length of tested plant species germinated either alone or in combination with others. The obtained results showed that seed germination and plant growth of cereals and vegetables are depended on the presence of other plants in all tested combinations. In this study has proven largely inhibitory allelopathic effect on germination and plant growth.
\end{abstract}

Keywords: allelopathy, cereals, vegetables.

\section{INTRODUCTION}

Allelopathy is chemical and ecological phenomenon which refers to the fact that competing organisms produce chemicals that inhibit the growth of members of their own or other species (EICHORN et al., 2014).

Allelopathy is an interference mechanism in which live or dead plant materials release chemical substances, called allelochemicals, which inhibit or stimulate the associated plant growth (MAY and ASH, 1990). According to PUTNAM (1988) chemical with allelopathic potential are presented (commonly in conjugated form) in almost all plants and in many tissues - leaves, stems, flowers, fruits, seeds and roots. Allelopathy may refers to beneficial or harmful effects, by release of chemicals from plant parts by leaching, root exudation, volatilization, residue decomposition and other processes in both natural and agricultural systems (CHOU, 1990; SINGH et al., 2001). Suitable manipulation of the allelopathy towards improvement of crop productivity and environmental protection through eco-friendly control of weeds, pests, crop diseases and synthesis of novel agrochemicals based of natural produce have gained attention of the scientists engaged in allelopathy research (SANG-UK et al.,2005).

Allelochemicals can act on the stage of germination, growth and development of sensitive plants. The most common changes causing the inhibition or retardation of germination, coleoptile elongation, root and shoot development of seedling (NARWAL, 1994). 
Chemical compounds formed in plants are usually by-products of basic chemical processes in the life of plants. A frequent cause of their increased secretion in plants is the stress (impact of diseases, pests, abiotic factors). Allelochemicals may arise and decommissioning of plants that secrete them. The most frequently mentioned allelopathy effects include reduced seed germination and reduced growth of the seed coast and seedling growth (DAIZY et al., 2001; FERGUSON and RATHINASABAPATHI, 2003).

Because of the extreme importance in recent years which is given to allelopathy in plants important for human consumption, and in order to contribute to a better understanding of allelopathic relationship between certain grains and vegetables, as well as to improving organic production, the aim of present paper was to determine the presence of allelopathic relations during germination of seeds and seedling growth of three cereals and three vegetable species.

\section{MATERIALS AND METHODS}

\section{Plant material}

Six cereal and vegetable species [wheat (Triticum aestivum L.), barley (Hordeum vulgare L.), oat (Avena sativa L.), spinach (Spinacia oleracea L.), radish (Raphanus sativus L.) and pepper (Capsicum annum L.)] were used in this study. These species were selected due to their agronomic importance. Cereal seeds are obtained from the Center of Small Grains in Kragujevac and vegetable seeds are bought in agricultural pharmacy. Seeds of wheatvariety Toplica, barley - variety Jadran and oat - variety Lovćen were collected from the harvest of 2012, while seeds of papper, spinach and radish were with a date of production from 2013.

At the start of experiments, seeds were surface disinfected in order to remove the epiphytic microflora, which may be specific to certain types of seeds. Disinfection is performed by soaking seeds in a $0.1 \%$ solution of bleach (sodium hypochlorite $\mathrm{NaClO}$ ) for 57 minutes. After disinfection, the seeds were washed five times with distilled water. Surface sterilized seeds are inoculated into Petri dishes.

\section{Experimental procedure}

Seeds from each species were placed on filter paper in $10 \mathrm{~cm}$ Petri dishes by the following layout:
1.30 seeds of wheat
2. 30 seeds of barley
3. 30 seeds of oat
4. 30 seeds of pepper
5. 30 seeds of spinach
6. 30 seeds of radish
7. 15 seeds of wheat +15 seeds of barley
8.15 seeds of wheat +15 seeds of oat
9. 15 seeds of barley +15 seeds of oat
10. 10 seeds of wheat +10 seeds of barley +10 seeds of oat
11. 15 seeds of pepper +15 seeds of spinach
12. 15 seeds of pepper +15 seeds of radish
13. 15 seeds of spinach +15 seeds of radish
14. 10 seeds of pepper +10 seeds of spinach +10 seeds of radish.

The dishes were moistened with $5 \mathrm{ml}$ of distilled water and kept in growth chamber at $16 / 8 \mathrm{~h}$ photoperiod and $22 \pm 1^{\circ} \mathrm{C}$. Distilled water was added to each Petri dish, during the 
experiment according to seeds water requests. The number of the germinated seeds and length of seedlings (root and hypocotyl elongation) was determined after seven days. Germination percentage (GP) is estimate of the viability of seeds. The equation to calculate germination percentage is:

$$
\mathrm{GP}=\frac{\text { seed germinated }}{\text { total seed number }} \times 100
$$

\section{Statistical analyzes}

All data were statistically evaluated with SPSS software package. The data are presented as mean values \pm S.E.M. $(\mathrm{n}=3)$. For comparison between samples, data was analyzed by the Student's $t-$ test. $p$ values $<0.05$ were considered statistically significant.

\section{RESULTS AND DISCUSSION}

\section{Seed germination}

In order to determine possible allelopathic effects, different combinations of seeds are placed in favorable conditions for germination. Obtained values, determined as percentage of germination, are presented in Figure 1 for cereal and Figure 2 for vegetable species, respectively.

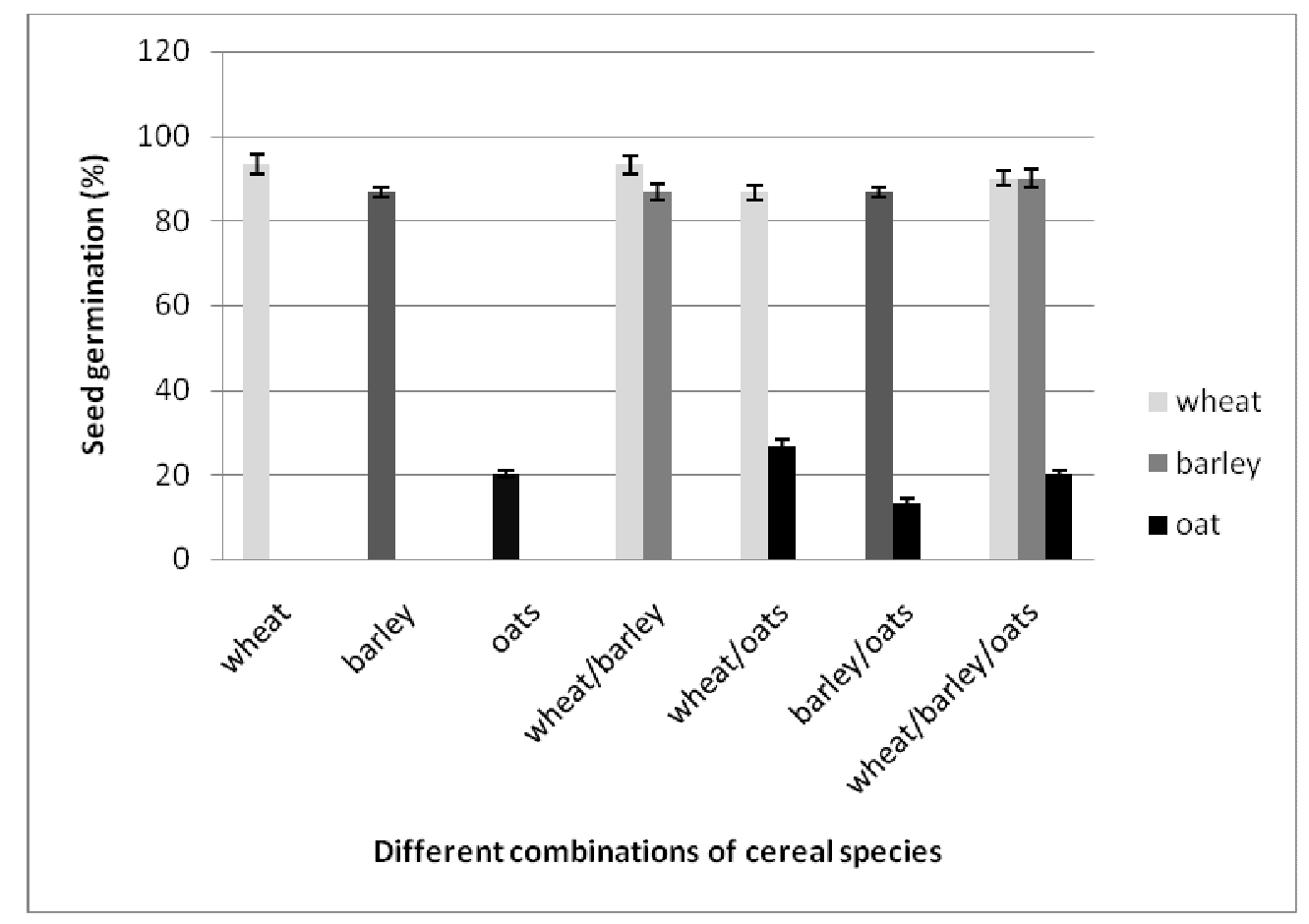

Figure 1. Allelopathic effect between selected cereals on seed germination.

On the basis of the obtained data, it is evident that there are allelopathic relations between the selected plant species. In the case of cereals, wheat seeds were inhibited to germinate in presence of oat (germination reduced 6.6\%), as well as in triple combinations (wheat + barley + oat) were germination was reduced $3.33 \%$ (Figure 1). In the presence of barley, wheat seeds were germinated in the same percentage as in the absence of other seeds. Barley seeds have shown same percentage of germination alone, or in combination with wheat and oat $(86.6 \%)$, while in triple combination is recorded slight increasing of 
germination $(3.34 \%)$. Oat seeds germinated in great percentage in presence of wheat (increasing in germination for 6.66\%), but in lower percentage in presence of barley seed.

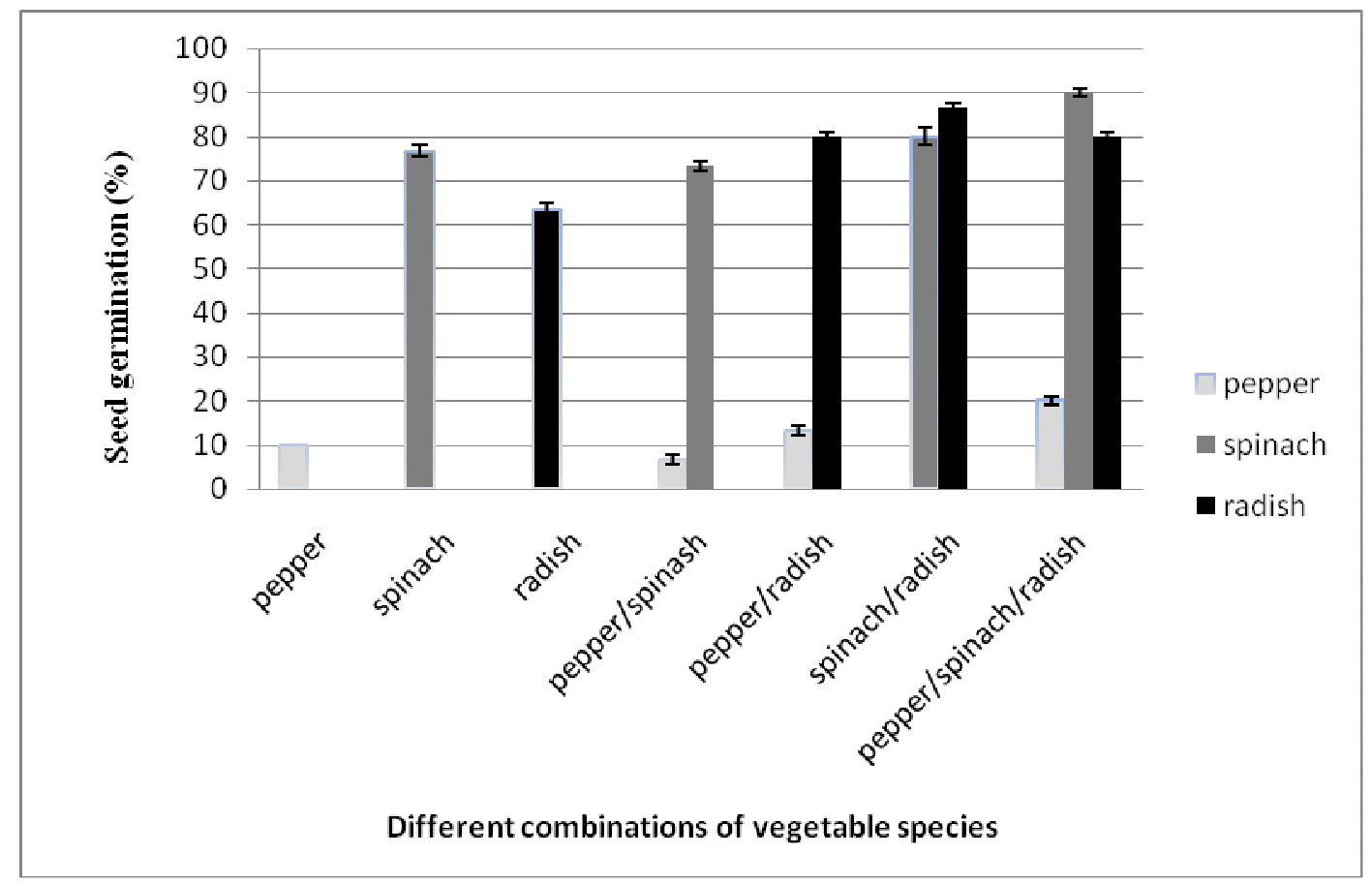

Figure 2. Allelopathic effect between selected vegetables on seed germination.

The seeds from vegetable species (pepper, spinach and radish) showed stronger allelopathic effects than the cereal seeds (Figure 2). Pepper seeds were stimulated to germinate in presence of radish seeds, especially in triple combination (germination increased for $10 \%$ ), while in presence of spinach seeds, germination was inhibited. Spinach seeds germinated in greater percentage in presence of radish seeds (germination increased for $3.34 \%$ ), and in the highest percentage in presence both spinach and radish (germination increased for $13.34 \%$ ). In the case of radish seeds, germination percentage was higher in all combinations with other vegetables, with the highest values obtained in combination with spinach (germination increased for 23.33\%).

\section{Seedling growth (elongation of root and stem)}

The inhibition in seedling growth was recorded in most of the tested seeds. Results for the root and stem length are presented in Table 1 . The root elongation is very influenced by the presence of other cereal species - allelopathic effects are expressed in the combination of all three plants, particularly in the case of oats (root length was decreased by $80.67 \%$ compared with seeds alone), but in the other combinations was presented markedly inhibitory allelopathic effect. Stimulatory allelopathic effect was recorded only in the root elongation of barley in combination with wheat (for 5.25\%).

When it comes to vegetable species, completely opposite effect was registered. The root elongation of spinach was very stimulated in the presence of the other two species, particularly in combination with radish where the root length was $89.2 \%$ more than in the case of radish alone. Unlike spinach, root elongation in pepper and radish were inhibited in combination with other species. Spinach had the strongest inhibitory effect on root elongation of pepper (root length was $53.7 \%$ less than in the case of pepper alone). 
Allelopathic effects were confirmed in the case of stem elongation, as well as root elongation (Table 1). The investigated cereal species have shown negative correlation in stem elongation, where are no stimulatory effects recorded in any case. Elongation of oat stem was remarkably inhibited in the presence of other cereals. In all combinations obtained values were lower (80-90\% longer than seeds alone). The young plants of barley and wheat were less sensitive on effects from other cereals; however, reduction in length was approximately $10 \%$, except in combination barley + wheat, where the growth of both plants was inhibited by the presence of the other.

Analyzing the results obtained for stem elongation of vegetable species, it can be noticed the lack of growth of pepper stem in all combinations. Unlike peppers, at spinach seeds was noted an increase in the length of the stem in all combinations, especially in the presence of radish, when the measured values were $58 \%$ higher. The pepper and the spinach had inhibitory effect on radish, whit reduction of length of 10-20\%.

Crop plants are known to release a diversity of allelochemicals into environment (phenolics or terpenoids) which generally represent secondary metabolites and provide plants defense strategies. However, some crops are less active in allelopathy because they are highly selected for physiological specialization of enhancing yields rather than developing endogenous chemicals for defense purposes (BATISH et al., 2001).

Upon release into crop environment, because of complex environmental conditions and microbial action, the nature and concentration of allelochemicals may change. Their action is often synergistic and their detrimental effects are dependent upon several abiotic and biotic factors (EINHELLING, 1996). Allelopathic activity of decomposing wheat and oat straw on some crop species has been reported by FAY et al. (1997) and DIAS (1991). In cereals such as wheat and barley a variety of allelochemicals have been identified including hydroxamic acids, cumarines, alkaloids, flavonoids and phenolic acids (WU et al., 2001b). The allelopathic activity of these cereals may arise from one or the combined action of a group of allelochemicals. Hydroxamic acids appear to be responsible for the allelopathic effect of wheat, maize and rye (SICKER et al., 2000; Wu et al., 2001a; MACIAS et al., 2005;COPAJA et al., 2006) and indole alkaloids in allelopathic effect of barley (BRAVO et al., 2010).

Capsaicin is a compound of Capsicum plant and several reports have shown the potential allelopathic effects of Capsicum plants on germination and plant growth (CHO et al., 1992; GONZÁLEZ et al., 1997); however, the physiological mechanism behind the Capsicum allelopathy needs further elucidation (SIDDIQUI et al., 2005). KABIR et al. (2010) have demonstrated spinach sensitivity on allelochemicals while allelopathic potential of wild radish was demonstrated by NORSWORTHY (2003).

The results of this study demonstrated that selected cereals, as well as vegetables contain some phytochemicals capable to affect seed germination and seedling growth of the tested species. The latitude of effects seemed to be dependent on the combinations of seeds, etc. involved species in allelopathy. Stronger allelopathic effect between vegetables is connected with the presence of higher concentrations of allelochemicals.

\section{References:}

[1] Batish, D.R., Singh, H.P., Kohli, R.K. and KaUR, S. (2001): Crop allelopathy and its role in ecological agriculture. p. 121-162. In: KoHLI, R.K., HARMindER, P.S. and BATISH, D.R. (ed.) Allelopathy in Agroecosystems. Food Products Press, New York. 
[2] Bravo, H.R., Iglesias, M.J., Copaja, S.V. and Argandona, V.H. (2010): Phytotoxicity of indole alkaloids from cereals. RevistaLatinoamericana de Química 38: 123-129.

[3] CHO, K.J., PARK, K.S. and TANG, C.S. (1992): Allelopathic potential of red-pepper (Capsicum annum L.) fruit. Research Report to Rural Development Administration 34: 18-23.

[4] Copaja, S.V., Villarroel, E., Bravo, H.R., Pizzarro, L. and Argandona, V.H. (2006): Hydroxamic acids in Secalecereale L. and the relationship with their antifeedant and allelopathic properties. Zeitschrift fur Naturforschung 61(c): 670-676.

[5] Daizy, R., Batish, H. P. and Singh, S. K. (2001): Crop allelopathy and its role in ecological agriculture, Journal of crop production 4 (2): 121-161.

[6] DiAS, L.S. (1991): Allelopathic activity of decomposing straw of wheat and oat and asso-ciated soil on some crop species. Soil \& Tillage Research. 21: 113-120.

[7] EICHORN, S.E., Evert, R.F. and RAVEn, P.H. (2014): Biologia vegetalia, 8 ed. Guanabara Koogan, Rio de Janeiro, Brasil, pp. 876.

[8] Einhelling, F.A. (1996): Interactions involving allelopathy in cropping systems. Agronomy Journal 88: 886-893.

[9] FAY, P. K. and DUKE, W. B. (1997): An assessment of allelopathic potential in Avenagermaplasm. Weed Sci. 25: 224-228.

[10] Ferguson, J.J. and Rathinasabapathi, B. (2003): Allelopathy: How Plants Suppress Other Plants. Horticultural Sciences Department, Florida Cooperative Extension Service.

[11] Gonzales, L., Souto, X.C. and Reigosa, M.J. (1997): Weed control by Capsicum annuum. Allelopathy Journal 4: 101-110.

[12] KabiR, A.K.M.S., Karim, S.M.R., Begum, M. and Juraimi, A.S. (2010): Allelopathic potential of rice varieties against spinach (Spinacia oleracea).International Journal of Agriculture and Biology 12: 809-815.

[13] Macias, F.A., Marin, D., Oliveros-Bastidas, A., Castellano, D., Simonet, A.M. and MoliniLlo, J.M.G. (2005): Structure-activity relationships (SAR) studies of Benzoxazolinones, their degradation products and analogues. Phytotoxicity on standard target species (STS). Journal Agricultural and Food Chemistry 53: 538-548.

[14] MAY, F.E. and ASH, J.E. (1990): An assessment of the allelopatic potential of eucalyptus. Aust. J. Bot. 38:245-254.

[15] NARWAL, S.S. (1994): Allelopathy in crop production. Scientific Publishers, Jodhpur, pp. 228.

[16] Norsworthy, J.K. (2003): Allelopathic potential of wild radish (Raphanus raphanistrum). Weed Technology 17: 307-313.

[17] Putnam, A.R. (1988): Allelochemicals from plants as herbicide. Weed Technology 2: 510-518.

[18] Sang-Uk, Ch., Hong-Gi, J., Dong-Kwan, K., Youngmin, K., Hee-Ock, B. and YoUNG-JIN, K. (2005): Allelopathic potential in lettuce (Lactuca sativa L.) plants. Sci. Hortic-Amsterdam 106: 309-317. 
[19] Sicker, D., Frey, M., Schulz, M. and Gierl, A. (2000): Role of natural benzoxazolinones in survival strategy of plants. In: Jeong, K. W. (ed). International review of cytology. A survey of cell biology. Academic press, San Diego. pp. 319-346.

[20] SiddiQui, Z.S. and UZ-ZAMAN, A. (2005): Effects of capsicum leachates on germination, seedling growth and chlorophyll accumulation in Vigna radiata (L.) Wilczek seedlings. Pakistan Journal of Botany 37 (4): 941-947.

[21] Singh, H.P., BAtish, D.R. and KoHLI, R.K. (2001): Allelopathy in Agroecosystems: An Overview. Journal of Crop Production 4 (2): 1-41.

[22] Wu, B. H., Pratley, J., Lemerle, D. and Haig, T. (2001): Allelopathy in wheat (Triticum aestivum). Ann. Appl. Biol. 139: 1-9.

[23] Wu, H., Haig, T., Pratley, J., Lemerle, D. and AN, M. (2001): Allelochemicals in wheat (Triticum aestivum L.) production and exudation of 2,4-dihydroxy-7-methoxy1,4-benzoxa-zin-3-one. Journal of Chemical Ecology 27: 1691-1700. 
Table 1. Allelopathic effects of selected cereals and vegetables on growth parameters.

\begin{tabular}{|c|c|c|c|c|}
\hline & Root lenght (cm) & Reduce (\%) & Stem lenght $(\mathbf{c m})$ & Reduce (\%) \\
\hline \multicolumn{5}{|l|}{ Cereal species } \\
\hline wheat & $4.86 \pm 0.84$ & & $2.36 \pm 0.55$ & \\
\hline barley & $8.18 \pm 0.21$ & & $4.83 \pm 0.04$ & \\
\hline oat & $2.38 \pm 0.23$ & & $0.77 \pm 0.19$ & \\
\hline wheat/barley & $3.65 \pm 0.58 / 8.61 \pm 0.91$ & $24.78 / 5.25$ & $1.66 \pm 0.2 / 4.15 \pm 0.3$ & $29.67 / 14.07$ \\
\hline barley/oat & $7.23 \pm 0.35 / 0.92 \pm 0.04$ & $11.61 / 61.34$ & $4.35 \pm 0.27 / 0.08 \pm 0.02$ & $9.93 / 89.61 *$ \\
\hline wheat/barley/oat & $3.77 \pm 0.35 / 7.34 \pm 0.38 / 0.46 \pm 0.05$ & $22.4 / 10.26 / 80.67 *$ & $2.14 \pm 0.27 / 4.37 \pm 0.36 / 0.12 \pm 0.01$ & $9.32 / 9.52 / 84.41^{*}$ \\
\hline \multicolumn{5}{|l|}{ Vegetable species } \\
\hline pepper & $1.21 \pm 0.06$ & & $0.56 \pm 0.02$ & \\
\hline pepper/radish & $1.12 \pm 0.19 / 6.1 \pm 0.35$ & $7.4 / 18.3$ & $0 / 5.63 \pm 0.93$ & $100 / 10$ \\
\hline spinach/radish & $5.26 \pm 0.27 / 6.53 \pm 0.33$ & $89.2 / 12.5$ & $0.98 \pm 0.08 / 6.07 \pm 0.35$ & $58 / 2.9$ \\
\hline pepper/spinach/radish & $1.1 \pm 0.09 / 4.36 \pm 0.45 / 4.47 \pm 0.7$ & $9.1 / 56.8 / 40.2^{*}$ & $0 / 0.90 \pm 0.39 / 4.93 \pm 0.87$ & $45.52 / 21.1$ \\
\hline
\end{tabular}

a - values are expressed as means \pm S.E.M.; ${ }^{*} p<0.05$ 